
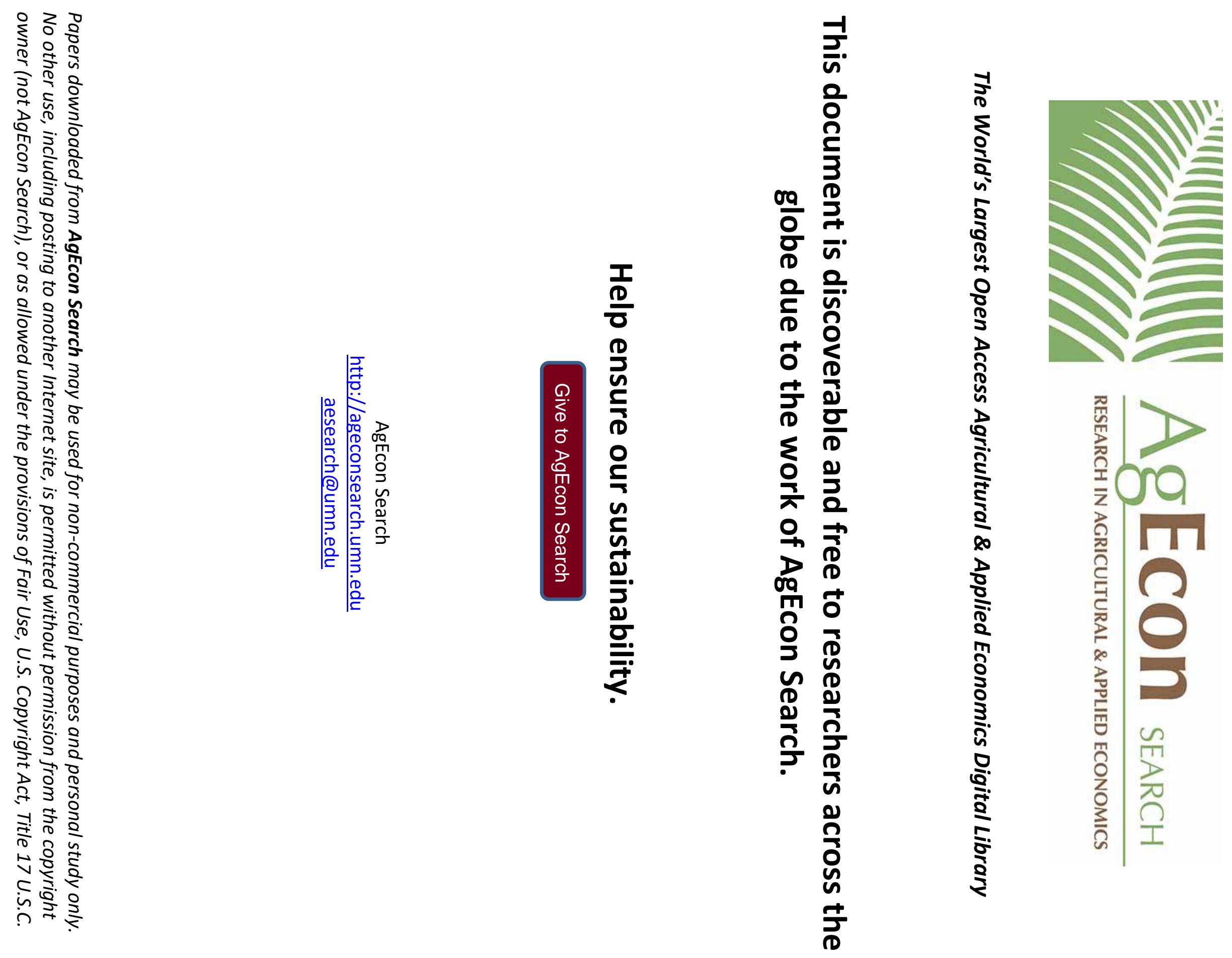
Gender and Policy Roles in Farm Household Diversification in Zambia

\author{
Mariana Saenz \\ Department of Finance and Economics \\ Georgia Southern University \\ E-mail:msayala@georgiasothern.edu
}

\author{
Eric Thompson \\ Department of Economics \\ University of Nebraska - Lincoln \\ E-mail:ethompson2@unl.edu
}

Selected Poster prepared for presentation for the 2015 Agricultural \& Applied Economics Association and Western Agricultural Economics Association Annual Meeting, San Francisco, CA, July 26-28.

Copyright 2015 by [Mariana Saenz, Eric Thompson]. All rights reserved.

Readers may make verbatim copies of this document for non-commercial purposes by any means, provided this copyright notice appears on all such copies. 


\section{Gender and Policy Roles in Farm Household Diversification in Zambia}

Mariana Saenz, Georgia Southern University Eric Thompson, University of Nebraska - Lincoln

\begin{abstract}
This paper uses two crop diversification indices and a multivariate regression model to empirically investigate the effect of Zambia's input subsidy program on crop allocation patterns and its relation to input subsidy program on crop allocation patterns and its relation to
gender. Results indicate that the subsidy program has increased land share allocation to maize, but it also allows households to increase the number of crops grown in the farm. The subsidy has also allowed female headed households to increase their crop diversification
\end{abstract}

\section{Objectives}

This paper empirically investigates the effects of Zambia's input subsidy program on crop allocation patterns and its relation to gender. I attempt to explore two important subjects:

1) Explore is whether the subsidy program affects crop allocation patterns for female headed farm households differently than male farmers.

2) Investigate the impact of the household's socio-economic and socio-demographic, market and farm characteristics, in relation to farm household's crop diversification.

\section{Survey Data}

The data comes for the 1999/2000 Post-Harvest Survey (PHS) and the first, second and third supplemental surveys to the 1999/2000 Post-Harvest Survey. Panel data for small scale households covers mainly the 1999/2000, 2002/03 and 2006/07 agricultural season. Maize prices comes from the 2001/2002 and 2005/06 Post-Harvest Surveys (PHS). Rainfall data for the $1997 / 1998$ to $2005 / 2006$ planting seasons come from 36 rainfall stations.

Source: Zambia Central Statistical Office (CSO), the Ministry of Agriculture and Cooperatives (MACO), the Food Security Research Project from the Food Research Group at Michigan State University and the Zambia Meteorological Department.

\section{Methods}

Theoretical Model : Benin, Smale, Pender (2006) agricultural household model.

(1) $D=D\left(\alpha_{i}^{*}\left(A, Y, \Delta_{H H}, \Delta_{F}, \Delta_{M}, S u b, G, S u b * G\right)\right)$

$D$ : Count and Shannon Indices.

(2) $\left.\alpha_{i j t}^{*}=f\left(A, Y, \Delta_{H H}, \Delta_{F}, \Delta_{M}, S u b, G, S u b * G\right)\right)$

Econometric Estimation:

(1) Count Index - Negative Binomial Distribution

Shannon Index - Tobit Regression

(2) Multivariate Regression Model using the Logit Transformation

\begin{tabular}{lcc}
\hline \multicolumn{3}{c|}{ Count Index Estimation ${ }^{1}$} \\
\hline \multicolumn{1}{c}{ Independent Variable } & Coefficient & p-value \\
\hline Household Head Gender & -0.00141 & 0.918 \\
Subsidy ${ }^{* *}$ & 0.03258 & 0.019 \\
Gender by Subsidy Interaction & 0.04175 & 0.15 \\
1. Using Negative Binomial Estimator & & \\
${ }^{*}$ Indicates significant effect at the $5 \%$ level & & \\
\end{tabular}

\begin{tabular}{|c|c|c|}
\hline \multicolumn{3}{|c|}{ Shannon Index Estimation ${ }^{1}$} \\
\hline Independent Variable & Coefficient & p-value \\
\hline Household Head Gender & -0.00058 & 0.973 \\
\hline Subsidy & 0.02668 & 0.161 \\
\hline Gender by Subsidy Interaction** & 0.09318 & 0.008 \\
\hline
\end{tabular}

\begin{tabular}{|c|c|c|c|}
\hline \multicolumn{4}{|c|}{ Multivariate Regression ${ }^{1}$} \\
\hline Independent Variable & Maize & Cassava & Groundnuts \\
\hline Household Head Gender & $-1.053^{* *}$ & 0.527 & $1.544^{*}$ \\
\hline Subsidy & $3.878^{*}$ & $-3.124^{*}$ & $1.035^{* *}$ \\
\hline Gender by Subsidy Interaction & 0.728 & -0.822 & 1.478 \\
\hline \multicolumn{2}{|l|}{ Independent Variable } & Seed Cotton & Millet \\
\hline \multicolumn{2}{|l|}{ Household Head Gender } & $-1.134^{*}$ & 0.241 \\
\hline \multicolumn{2}{|l|}{ Subsidy } & -0.389 & $-0.737 * *$ \\
\hline \multicolumn{2}{|l|}{ Gender by Subsidy Interaction } & 0.065 & -0.628 \\
\hline \multicolumn{4}{|c|}{$\begin{array}{l}1 \text { Estimation for the five major Crops. } \\
*, * * \text { Indicates significant effects at the } 1 \% \text { and } 5 \% \text { respectively }\end{array}$} \\
\hline \multicolumn{4}{|c|}{ Conclusion } \\
\hline
\end{tabular}

Results from the Count Diversification Index show that the subsidy program significantly increases the expected number of crops grown in the farm.

- The Shannon Diversification Index shows that among subsidized households, female headed households have greater crop proportional abundance across the farm than male headed households.

- The multivariate regression estimation indicates that the subsidy program increases the land share allocation to maize and groundnuts, but decreases it for cassava and millet

\section{References}

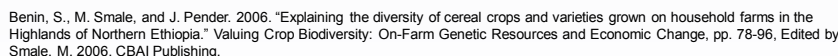
Contact Information: msaenz@huskers.unl.edu 